\title{
Caracterização Anatômica Macroscópica de Madeiras Folhosas Comercializadas no Estado do Espírito Santo
}

\author{
Rejane Costa Alves ${ }^{1}$, José Tarcísio da Silva Oliveira ${ }^{2}$ \\ Javan Pereira Motta ${ }^{3}$, Juarez Benigno Paes ${ }^{2}$
}

\begin{abstract}
${ }^{1}$ Departamento de Engenharia de Estruturas, Universidade Federal de Minas Gerais - UFMG ${ }^{2}$ Departamento de Engenharia Florestal - DEF, Universidade Federal do Espírito Santo - UFES

${ }^{3}$ Departamento de Ciências Florestais - DCF, Universidade Federal de Lavras - UFLA
\end{abstract}

\begin{abstract}
RESUMO
Para melhor identificação da madeira, é necessário fazer um estudo criterioso de sua estrutura anatômica, já que cada espécie possui estrutura anatômica única e diferente. O estudo anatômico da madeira leva a um método seguro e prático para identificação das madeiras e se baseia na descrição dos tipos e frequências das células e dos tecidos do xilema secundário das espécies lenhosas. No reconhecimento das madeiras, as características gerais, como massa específica aparente, aspectos estéticos e propriedades organolépticas são também de fundamental importância. Portanto, este estudo teve como objetivo determinar as características anatômicas macroscópicas das madeiras de folhosas comercializadas no Estado do Espírito Santo, em face da carência de ferramentas disponíveis para a identificação de madeiras comerciais. Este estudo foi realizado por meio de ferramentas simples, como uma faca para alisamento da superfície da amostra e uma lupa com aumento de até $10 \times$, seguindo especificações da Comissão Panamericana de Normas Técnicas - COPANT. Neste trabalho, foram abordadas características sensoriais, como cor, brilho, cheiro, textura, densidade básica, resistência ao corte, figura ou desenho, e distinção entre cerne e alburno, além de se verificarem características anatômicas, como grã, camadas de crescimento, raio, parênquima e poros.
\end{abstract}

Palavras-chave: comércio madeireiro, características organolépticas, macroscopia.

\section{Macroscopic Anatomical Characterization of the Hardwood Marketed in the State of Espirito Santo, Brazil}

\begin{abstract}
In order to better identify the timber, a careful study of its anatomical structure must be made, since each species has unique and different anatomical structures. The study of wood anatomy is a safe and practical method based on cellular description and aesthetic and organoleptic aspects of timber. To this end, this study was intended to determine the gross anatomical features of the hardwood marketed in the State of Espirito Santo, given the lack of tools available for the identification of commercial timbers. This study was developed through the use of simple tools, such as a knife for smoothing the sample surface and a magnifying glass (10x), according to the specifications of the Pan-American Commission of Technical Standards - COPANT. This research addressed sensory characteristics such as color, brightness, smell, texture, density, shear strength, figure or drawing distinction between heartwood and sapwood, and anatomic features like grain, growth layers, ray, parenchyma and pores.
\end{abstract}

Keywords: timber trade, organoleptic characteristics, macroscopic. 


\section{INTRODUÇÃO}

O Estado do Espírito Santo possui uma grande vocação florestal, com as áreas de produção de florestas plantadas, apresenta grande potencial representativo, quando comparado à área total de florestas plantadas no país. Tais florestas são em boa parte pertencentes a empresas produtoras de celulose, mas também estão em pequenas propriedades por meio de programas de fomento.

Em 2008, com a crise mundial, assim como todos os setores da economia, o setor florestal passou por déficit quanto ao consumo interno e às exportações de madeira, formando um cenário totalmente prejudicial ao setor. No entanto, em 2009, a economia mundial se manteve em recuperação e respondeu como mais um ano promissor para o setor florestal. Com o aumento da comercialização da madeira, acentuou-se ainda mais a necessidade de sua correta identificação, para que tais madeiras sejam utilizadas de forma adequada, uma vez que o primeiro passo no uso de determinado bem é sua correta identificação. Visto que, no processo de transformação da árvore em madeira serrada, várias de suas características, como folhas, frutos e flores, serão eliminadas, as características do lenho se tornam a base de identificação da espécie florestal.

De acordo com Nahuz (2004), o mercado mundial de madeira variou de 19 a 22 milhões de metros cúbicos, havendo assim uma crescente comercialização de madeira serrada ao longo dos anos, em 2009, de acordo com a Food and Agriculture Organization - FAO, a produção de madeira serrada foi de aproximadamente 25 milhões de metros cúbicos (Centro de Inteligência em Florestas, 2011). O material madeira ocupa lugar de destaque no segmento industrial não apenas nos países subdesenvolvidos, mas também nos desenvolvidos. De acordo com Zenid (2007), a Associação Europeia de Indústrias da Madeira afirmou que, em 2010, a madeira se tornaria o material líder no Continente Europeu, visto que sua base florestal emprega 2,7 milhões de pessoas e gera cerca de 165 bilhões de euros por ano. A Agência Pará (2010) afirmou que a Secretaria de Estado de Meio Ambiente liberou $1.839 .489,621 \mathrm{~m}^{3}$ de matéria-prima florestal, em toras e resíduos, para setores produtores de madeira no período de janeiro a abril de 2010.
Para produção de madeiras, se destacam os grupos das coníferas e folhosas. Segundo Chimelo (1992), as coníferas, do ponto de vista da anatomia da madeira, apresentam estrutura homogênea, o que justifica a dificuldade de sua identificação. Estas se caracterizam, de uma forma geral, por ausência de poros ou vasos, presença de raios estreitos ou finos, fibras longas, densidade baixa e baixa resistência ao corte. No entanto, percebe-se que o autor generalizou as características de densidade baixa e dureza do corte para todas as espécies do grupo, o que não é aconselhável, visto que nem sempre a afirmativa é verdadeira, como, por exemplo, na madeira de teixo (Taxus baccata), gimnosperma que possui madeira resistente ao corte manual.

Quanto às folhosas, percebe-se que o autor novamente generalizou as madeiras pertencentes ao grupo, quando menciona possuir estrutura mais heterogênea, presença de vasos ou poros, fibras curtas e estreitas, duras ao corte, densidade média a alta e com cernes de cores bastante variáveis. Note-se que, em relação à densidade e resistência ao corte, devese tomar cuidado com qualquer generalização, uma vez que dentro do grupo das folhosas ocorre grande variação dessas características, seja a densidade variando de baixa a alta, ou mesmo possuir baixa resistência ao corte. Para reforçar a afirmativa, observa-se a diferença entre duas madeiras do grupo, balsa e aroeira-do-sertão: a primeira espécie é uma das mais leves e macias, e a segunda é uma das madeiras mais densas e de elevada dureza.

O conhecimento da estrutura anatômica é, sem dúvida, uma importante ferramenta para a identificação da madeira, sendo também de fácil aplicação para a sua correta nomenclatura. No entanto, essa correta identificação depende de treinamento, conhecimento e habilidade do responsável por esse estudo. Vale destacar também que, em uma prática de identificação de madeira, deve-se buscar colocar o nome científico correspondente a um determinado nome popular, uma vez que, comercialmente, uma madeira possui vários nomes populares (Zenid, 2007).

A identificação botânica da madeira permite $\mathrm{o}$ acesso às suas propriedades, geralmente disponíveis em bancos de dados, como em atlas de identificação, visto que estes servem de base para identificações e uso correto da madeira a ser utilizada (Zenid \& Ceccantini, 2007). 
Este trabalho justifica-se pela da falta de informações a respeito das espécies de madeira comercializadas atualmente no Estado do Espírito Santo e também por colaborar com a correta identificação dessas madeiras pelo próprio comércio de produtos florestais do Estado. Este trabalho teve, portanto, como objetivo descrever as principais madeiras comercializadas no Estado do Espírito Santo no que diz respeito às suas características gerais, organolépticas e anatômicas no nível macroscópico.

\section{MATERIAL E MÉTODOS}

\subsection{Madeiras estudadas}

As madeiras estudadas foram selecionadas de acordo com a necessidade de conhecimento de identificação de madeiras comercializadas no Estado do Espírito Santo.

As madeiras descritas neste estudo foram de Angelim-pedra (Hymenolobium petraeum), Cedro (Cedrela fissilis), Garapa (Apuleia leiocarpa), Ipê-preto (Zeyheria tuberculosa), Jatobá (Hymenaea courbaril), Paraju (Manilkara longifolia), Pau-amarelo (Euxylophora paraensis), Perobamica (Aspidosperma populifolium) e algumas madeiras de eucalipto, como Eucalipto cloeziana (Eucalyptus cloeziana), Eucalipto citriodora (Corymbia citriodora) e Eucalipto grandis (Eucalyptus spp.), todas comercializadas no Estado do Espírito Santo.

\subsection{Preparo das amostras}

As amostras das madeiras foram disponibilizadas pelo Laboratório de Ciência da Madeira - LCM, do Departamento de Engenharia Florestal - DEF, do Centro de Ciências Agrárias - CCA, da Universidade Federal do Espírito Santo - UFES, no município de Jerônimo Monteiro-ES.

Foram preparados corpos de prova, com dimensões de $2,0 \times 2,0 \times 3,0 \mathrm{~cm}$, sendo a última no sentido das fibras; as peças passaram por cozimento para amolecimento e um posterior alisamento foi realizado em um micrótomo de deslize manual da marca Leica modelo SM 2000R. Em seguida, efetuouse o processo de lixamento das peças com lixa de grão abrasivo de óxido de alumínio e granulometria 1200, para conseguir perfeita superfície a ser utilizada para obtenção de fotomacrografias. Para a retirada do pó da lixa, as amostras foram sopradas com ar comprimido.

\subsection{Macrofotografia das amostras}

As fotomacrografias das seções transversais das amostras das madeiras foram realizadas na sede da Polícia Federal do Espírito Santo, no município de Vila Velha, com o uso de câmera digital da marca NIKON, modelo D2X, 12.2 Mega pixels, acoplada à lente NIKON AF MICRO NIKKOR $60 \mathrm{~mm} \mathrm{f/2.8D,}$ sendo utilizado o software Microsoft Office Picture Manager. Vale destacar que as fotomacrografias de seções transversais são responsáveis pela identificação das madeiras em campo.

\subsection{Caracterização anatômica das madeiras}

Para os estudos anatômicos das madeiras, seguiram-seas recomendações dos procedimentos em estudos de anatomia de madeira da COPANT (1974). Para auxílio na correta identificação das madeiras, foi utilizada a chave de identificação anatômica do Instituto de Pesquisas Tecnológicas - IPT (1983).

\section{RESULTADOS E DISCUSSÃO}

A seguir, encontram-se as descrições das características gerais e macroscópicas, bem como apresentada a fotomacrografia da seção transversal das principais madeiras de folhosas comercializadas no Espírito Santo.

Nome vulgar: Angelim-pedra

Nome científico: Hymenolobium petraeum Ducke

Família: Fabaceae

\section{Descrição geral}

A madeira possui diferença entre cerne e alburno distinto, com coloração castanho amarelado, brilho moderado, cheiro característico quando verde e gosto imperceptível. Possui massa específica aparente alta, com valor de 1,00 g. $\mathrm{cm}^{-3}$ a $15 \%$ de umidade, dura ao corte manual no plano transversal, grã direita e textura grossa. Apresenta figura ou desenho destacado por parênquima axial em faixas longitudinais e camadas de crescimento distintas.

\section{Descrição macroscópica}

No plano transversal (Figura 1), os poros são visíveis a olho nu, com porosidade difusa, arranjo 
radial, solitários e múltiplos, vazios na maioria das vezes, e obstruídos por substâncias esbranquiçadas. O parênquima axial é visível a olho nu, do tipo paratraqueal aliforme de extensão losangular, formando faixas confluentes. O parênquima radial é visível a olho nu. As camadas de crescimento são demarcadas por parênquima marginal.

No plano longitudinal tangencial, os raios são visíveis somente sob lente de $10 \times$ e estratificados, com listrado de estratificação regular. As linhas vasculares são retilíneas. No plano longitudinal radial, o espelhado dos raios é pouco contrastado.

Nome vulgar: Cedro

Nome científico: Cedrela fissillis Vell.

Família: Meliaceae

\section{Descrição geral}

A madeira possui diferença entre cerne e alburno distinto, com coloração castanho avermelhado, brilho acentuado, cheiro característico e gosto ligeiramente amargo. Possui massa específica aparente média, com valor de 0,53 g.cm ${ }^{-3}$ a $15 \%$ de umidade, macia ao corte manual no plano transversal, grã direita e textura média. Apresenta figura e desenho presente em função do espelhado dos raios e as camadas de crescimento são distintas.

\section{Descrição macroscópica}

No plano transversal (Figura 2), os poros são visíveis a olho nu, porosidade em anéis semiporosos, arranjo tangencial, em sua maioria, solitários e vazios. O parênquima axial é visível sob lente de $10 \times$, do tipo paratraqueal vasicêntrico e faixas. $\mathrm{O}$ parênquima radial é visível sob lente de $10 \times$. As camadas de crescimento são individualizadas por parênquima marginal e por distribuição dos poros de grandes diâmetros no lenho inicial.

No plano longitudinal tangencial, o parênquima radial possui visibilidade a olho nu, com listrado de estratificação irregular. As linhas vasculares são retilíneas. No plano longitudinal radial, o espelhado dos raios é contrastado.

Nome vulgar: Eucalipto citriodora

Nome científico: Corymbia citriodora (Hook.) K.D.Hill \& L.A.S.Johnson

Família: Myrtaceae

\section{Descrição geral}

A madeira possui diferença entre cerne e alburno distinto, com coloração amarelo pardacento escuro, brilho ausente, cheiro e gosto imperceptíveis. Possui massa específica aparente alta, com valor de 1,04 g. $\mathrm{cm}^{-3}$ a $15 \%$ de umidade, dura ao corte manual no plano transversal, grã ondulada e textura fina a média. Não apresenta figura ou desenho e as camadas de crescimento são pouco distintas.

\section{Descrição macroscópica}

No plano transversal (Figura 3), os poros são visíveis a olho nu, porosidade difusa, arranjo radial e diagonal, solitários e múltiplos, e, na maioria das vezes, obstruídos por tiloses. O parênquima axial é pouco visível mesmo sob lente de $10 \times$, do tipo paratraqueal vasicêntrico a aliforme. $O$ parênquima radial é visível sob lente de $10 \times$. As camadas de crescimento são individualizadas por zonas fibrosas tangenciais mais escuras e pela mudança na orientação dos poros.

No plano longitudinal tangencial, o parênquima radial é pouco visível sob lente de $10 \times$, com listrado de estratificação irregular. As linhas vasculares são irregulares. No plano longitudinal radial, o espelhado dos raios é ausente.

Nome vulgar: Eucalipto cloeziana

Nome científico: Eucalyptus cloeziana F. Muell

Família: Myrtaceae

\section{Descrição geral}

A madeira possui diferença entre cerne e alburno distinto, com coloração amarelo pardo claro, brilho moderado, cheiro e gosto imperceptíveis. Possui massa específica aparente alta, com valor de 0,86 g.cm ${ }^{-3}$ a $15 \%$ de umidade, dura ao corte manual no plano transversal, grã direita e textura fina. Não apresenta figura ou desenho e as camadas de crescimento são pouco distintas.

\section{Descrição macroscópica}

No plano transversal (Figura 4), os poros são visíveis sob lente de $10 \times$, porosidade difusa, arranjo diagonal, maioria solitários e, na maioria das vezes, são obstruídos por tiloses. O parênquima axial é visível somente sob lente de $10 \times$. O parênquima radial é visível sob lente de 10×. As camadas de crescimento são individualizadas por zonas fibrosas tangenciais mais escuras.

No plano longitudinal tangencial, o parênquima radial é pouco visível sob lente de $10 \times$, com listrado de estratificação irregular. As linhas vasculares são 
retilíneas. No plano longitudinal radial, o espelhado dos raios é ausente.

Nome vulgar: Eucalipto grandis

Nome científico: Eucalyptus spp.

Família: Myrtaceae

\section{Descrição geral}

A madeira possui diferença entre cerne e alburno distinto, com coloração rosada, brilho moderado e cheiro e gosto imperceptíveis. Possui massa específica aparente média com valor de $0,56 \mathrm{~g}_{\mathrm{cm}} \mathrm{cm}^{-3}$ a $15 \%$ de umidade, macia ao corte manual no plano transversal, grã direita e textura média. Não apresenta figura ou desenho e as camadas de crescimento são distintas.

\section{Descrição macroscópica}

No plano transversal (Figura 5), os poros são visíveis a olho nu, porosidade difusa, arranjo diagonal, maioria solitários e, às vezes, obstruídos por tiloses. O parênquima axial é visível sob lente de $10 \times$, do tipo paratraqueal vasicêntrico. $O$ parênquima radial é visível sob lente de $10 \times$. As camadas de crescimento são individualizadas por zonas fibrosas tangenciais mais escuras e mudança de orientação dos poros.

No plano longitudinal tangencial, os raios são pouco visíveis sob lente de $10 \times$, com listrado de estratificação irregular. As linhas vasculares são retilíneas. No plano longitudinal radial, os espelhados dos raios são ausentes.

\section{Nome vulgar: Garapa}

Nome científico: Apuleia leiocarpa (Vog.) Macbr.

Família: Leguminosae

\section{Descrição geral}

A madeira possui diferença entre cerne $\mathrm{e}$ alburno distinto, com coloração amarelo claro, brilho moderado, cheiro e gosto imperceptíveis. Possui massa específica aparente alta, com valor de $0,83 \mathrm{~g} \cdot \mathrm{cm}^{-3}$ a $15 \%$ de umidade, moderadamente dura ao corte manual no plano transversal, grã direita e textura fina. Não apresenta figura ou desenho e as camadas de crescimento são distintas.

\section{Descrição macroscópica}

No plano transversal (Figura 6), os poros são visíveis sob lente de $10 \times$, com porosidade difusa, arranjo diagonal e radial, solitários e múltilplos, e vazios. O parênquima axial é visível sob lente de 10×, do tipo paratraqueal aliforme e confluente formando faixas estreitas irregulares. O parênquima radial é visível sob lente de $10 \times$. As camadas de crescimento são individualizadas por zonas fibrosas tangenciais mais escuras.

No plano longitudinal tangencial, o parênquima radial é visível sob lente de $10 \times$, com listrado de estratificação regular. As linhas vasculares são retilíneas. No plano longitudinal radial, o espelhado dos raios é ausente.

Nome vulgar: Ipê-preto

Nome científico: Zeyheria tuberculosa (Vell.) Bur.

Família: Bignoniaceae

\section{Descrição geral}

A madeira possui diferença entre cerne $e$ alburno distinto, com coloração castanho escuro, brilho moderado, cheiro e gosto imperceptíveis. Possui massa específica aparente alta, com valor de $0,96 \mathrm{~g} \cdot \mathrm{cm}^{-3}$ a $15 \%$ de umidade, dura ao corte manual no plano transversal, grã direita e textura fina. Não apresenta figura ou desenho e as camadas de crescimento são distintas.

\section{Descrição macroscópica}

No plano transversal (Figura 7), os poros são visíveis a olho nu, porosidade difusa, arranjo radial, maioria solitários, às vezes obstruídos por tiloses. $\mathrm{O}$ parênquima axial é indistinto sob lente de $10 \times$. O parênquima radial pode ser visível sob lente de $10 \times$. As camadas de crescimento são individualizadas por zonas fibrosas tangenciais mais escuras e com menor frequência de poros.

No plano longitudinal tangencial, o parênquima radial possui visibilidade sob lente de $10 \times$, estratificado, com listrado de estratificação regular. As linhas vasculares são retilíneas. No plano longitudinal radial, o espelhado dos raios é pouco contrastado.

\section{Nome vulgar: Jatobá}

Nome científico: Hymenaea courbaril Duke

Família: Caesalpiniaceae

\section{Descrição geral}

A madeira possui diferença entre cerne e alburno distinto, com coloração castanho amarelado, brilho moderado, cheiro e gosto imperceptíveis. Possui massa específica aparente alta, com valor de 0,96 g.cm ${ }^{-3}$ a $15 \%$ de umidade, dura ao corte manual no plano transversal, grã direita e textura fina. 
Não apresenta figura ou desenho e as camadas de crescimento são distintas.

\section{Descrição macroscópica}

No plano transversal (Figura 8), os poros são visíveis a olho nu, porosidade difusa, arranjo radial a diagonal, solitários e múltiplos, vazios com pouca frequência de tiloses. O parênquima axial é visível a olho nu, do tipo paratraqueal aliforme, vasicêntrico e em faixas marginais. $O$ parênquima radial é visível a olho nu. As camadas de crescimento são individualizadas por parênquima marginal.

No plano longitudinal tangencial, o parênquima radial é visível sob lente de $10 \times$, com listrado de estratificação irregular. As linhas vasculares são retilíneas. No plano longitudinal radial, o espelhado dos raios é pouco contrastado.

Nome vulgar: Paraju

Nome científico: Manilkara longifolia (A. DC.) Dub.

Família: Sapotaceae

\section{Descrição geral}

A madeira possui diferença entre cerne e alburno distinto, com coloração castanho avermelhado escuro, brilho moderado, cheiro e gosto imperceptíveis. Possui massa específica aparente alta, com valor de 1,00 g.cm ${ }^{-3}$ a $15 \%$ de umidade, dura ao corte manual no plano transversal, grã ligeiramente inclinada e textura fina. Não apresenta figura ou desenho e as camadas de crescimento são indistintas.

\section{Descrição macroscópica}

No plano transversal (Figura 9), os poros são visíveis sob lente de $10 \times$, porosidade difusa, arranjo radial, solitários e múltiplos, parcialmente obstruídos por tiloses. O parênquima axial é visível sob lente de 10×, do tipo em linhas finas e irregulares. O parênquima radial é visível sob lente de $10 \times$. As camadas de crescimento são indistintas.

No plano longitudinal tangencial, o parênquima radial é invisível mesmo sob lente de 10×. As linhas vasculares são irregulares. No plano longitudinal radial, o espelhado dos raios é ausente.

Nome vulgar: Pau-amarelo

Nome científico: Euxylophora paraensis Huber

Família: Rutaceae

\section{Descrição geral}

A madeira possui diferença entre cerne e alburno distinto, com coloração amarela, brilho acentuado, cheiro e gosto imperceptíveis. Possui massa específica aparente alta, com valor de $0,84 \mathrm{~g}_{\mathrm{gcm}}^{-3} \mathrm{a}$ $15 \%$ de umidade, moderadamente dura ao corte manual no plano transversal, grã direita e textura fina. Não apresenta figura ou desenho e as camadas de crescimento são indistintas.

\section{Descrição macroscópica}

No plano transversal (Figura 10), os poros são visíveis somente sob lente de $10 \times$, porosidade difusa, arranjo radial, maioria múltiplos, parcialmente obstruídos por tiloses. O parênquima axial é invisível mesmo sob lente de $10 \times$. O parênquima radial é visível a olho nu. As camadas de crescimento são individualizadas por zonas fibrosas tangenciais mais escuras.

No plano longitudinal tangencial, o parênquima radial é visível sob lente de $10 \times$, com listrado de estratificação irregular. As linhas vasculares são retilíneas. No plano longitudinal radial, o espelhado dos raios é pouco contrastado.

Nome vulgar: Peroba-mica

Nome científico: Aspidosperma populifolium A. DC.

Família: Apocynaceae

\section{Descrição geral}

A madeira possui diferença entre cerne e alburno distinto, com coloração pardo amarelado, ausência de brilho, cheiro e gosto imperceptíveis. Possui massa específica aparente moderadamente alta, com valor de 0,73 g.cm ${ }^{-3}$ a $15 \%$ de umidade, dura ao corte manual no plano transversal, grã direita e textura fina. Não apresenta figura ou desenho e as camadas de crescimento são distintas.

\section{Descrição macroscópica}

No plano transversal (Figura 11), os poros são visíveis sob lente de $10 \times$, porosidade difusa, arranjo diagonal, maioria solitários, algumas vezes obstruídos por tiloses. O parênquima axial é invisível mesmo sob lente de $10 \times$. O parênquima radial é visível sob lente de $10 \times$. As camadas de crescimento são individualizadas por zonas fibrosas tangenciais mais escuras.

No plano longitudinal tangencial, o parênquima radial é invisível mesmo sob lente de 10×, com listrado de estratificação irregular. As linhas vasculares são retilíneas. No plano longitudinal radial, o espelhado dos raios é ausente. 


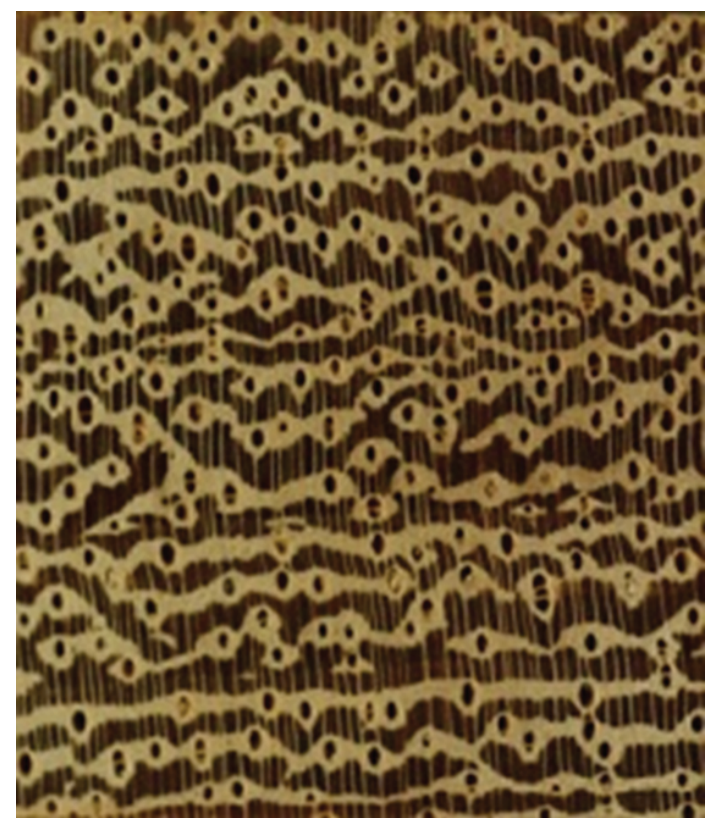

Figura 1. Fotomacrografia da madeira de Hymenolobium petraeum - plano transversal, $10 \times$.

Figure 1. Photomacrograph of the Hymenolobium petraeum wood - transverse plane, $10 \times$.

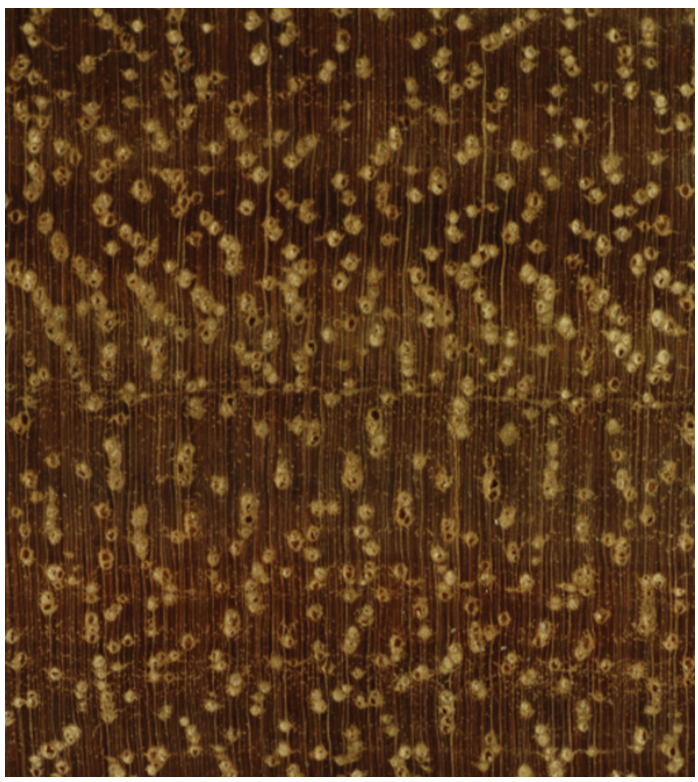

Figura 3. Fotomacrografia da madeira de Corymbia citriodora - plano transversal, $10 \times$.

Figure 3. Photomacrograph of the Corymbia citriodora wood - transverse plane, $10 \times$.

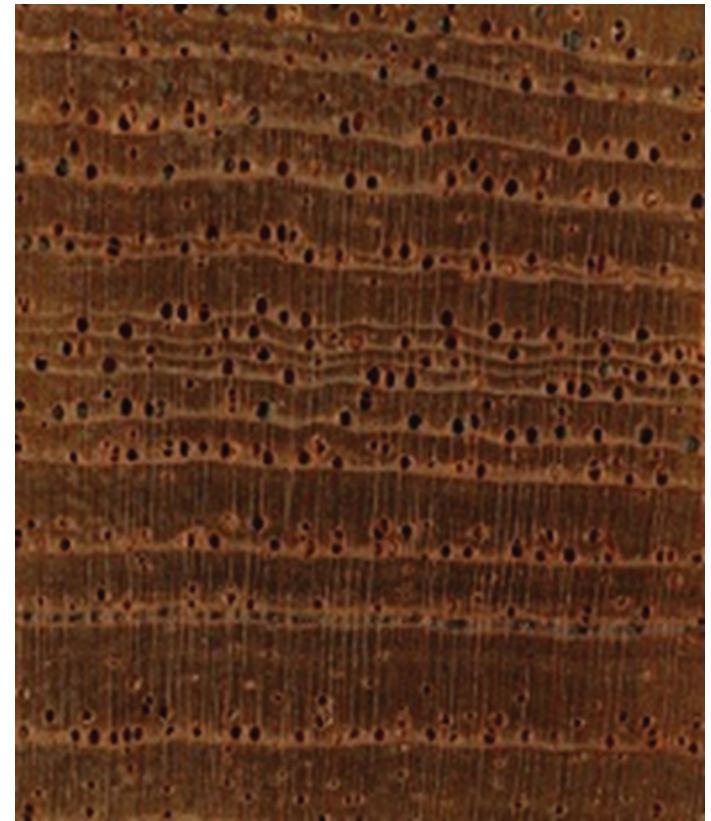

Figura 2. Fotomacrografia da madeira de Cedrela fissillis - plano transversal, $10 \times$.

Figure 2. Photomacrograph of the Cedrela fissillis wood - transverse plane, $10 \times$.

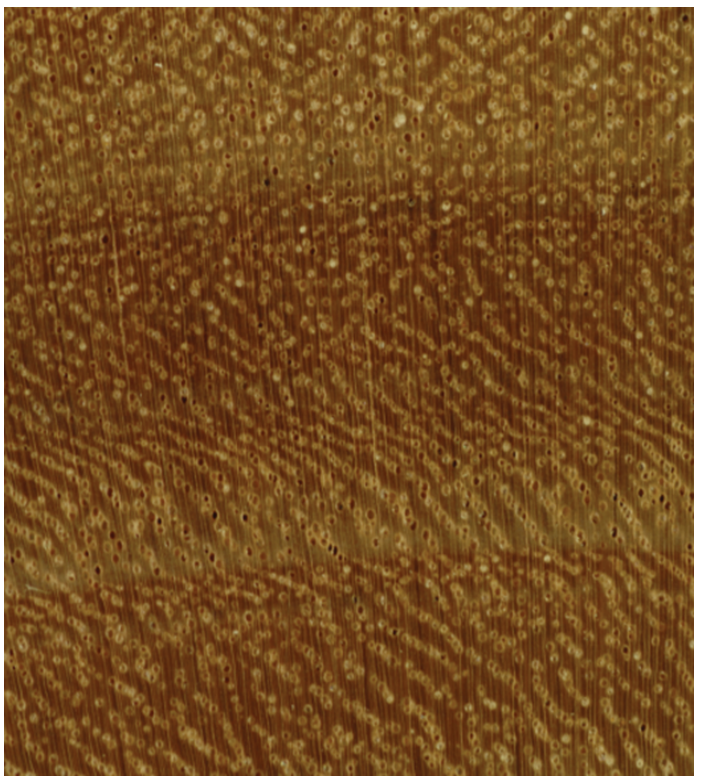

Figura 4. Fotomacrografia da madeira de Eucalyptus cloeziana - plano transversal, $10 \times$.

Figure 4. Photomacrograph of the Eucalyptus cloeziana wood - transverse plane, $10 \times$. 


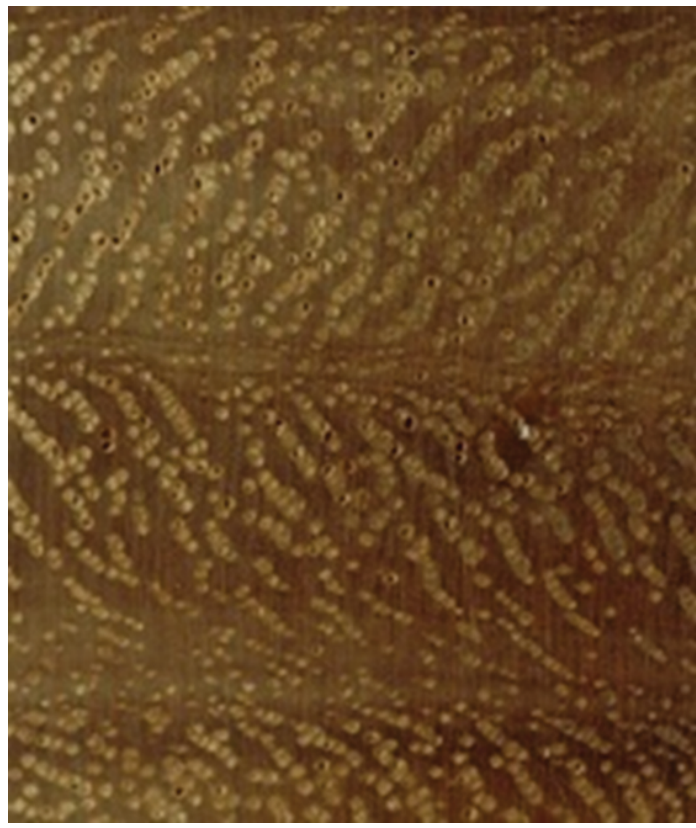

Figura 5. Fotomacrografia da madeira de Eucalyptus spp. - plano transversal, 10×.

Figure 5. Photomacrograph of the Eucalyptus spp. wood - transverse plane, $10 \times$.

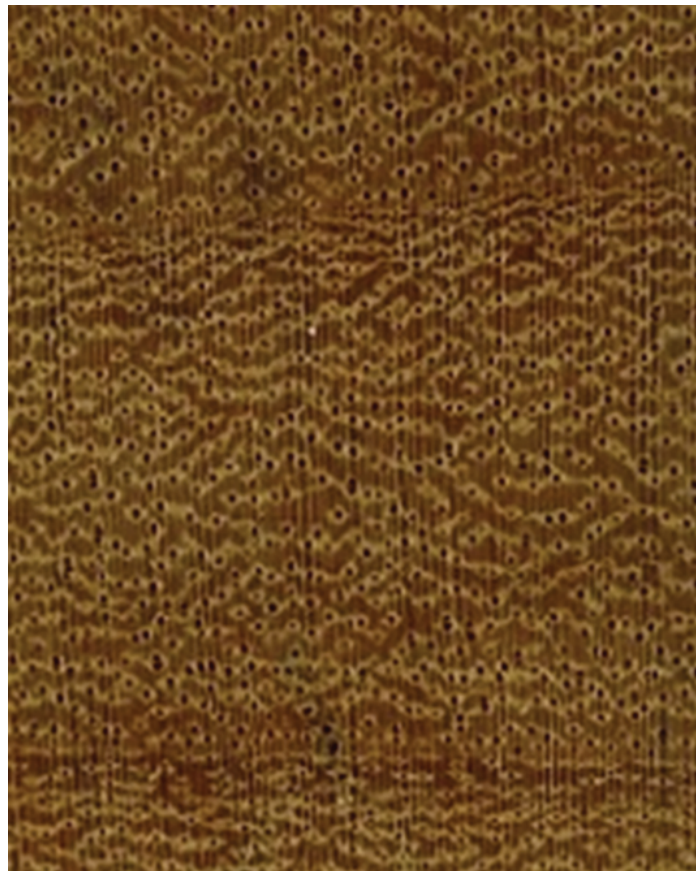

Figura 6. Fotomacrografia da madeira de Apuleia leiocarpa - plano transversal, $10 \times$

Figure 6. Photomacrograph of the Apuleia leiocarpa wood - transverse plane, $10 \times$.

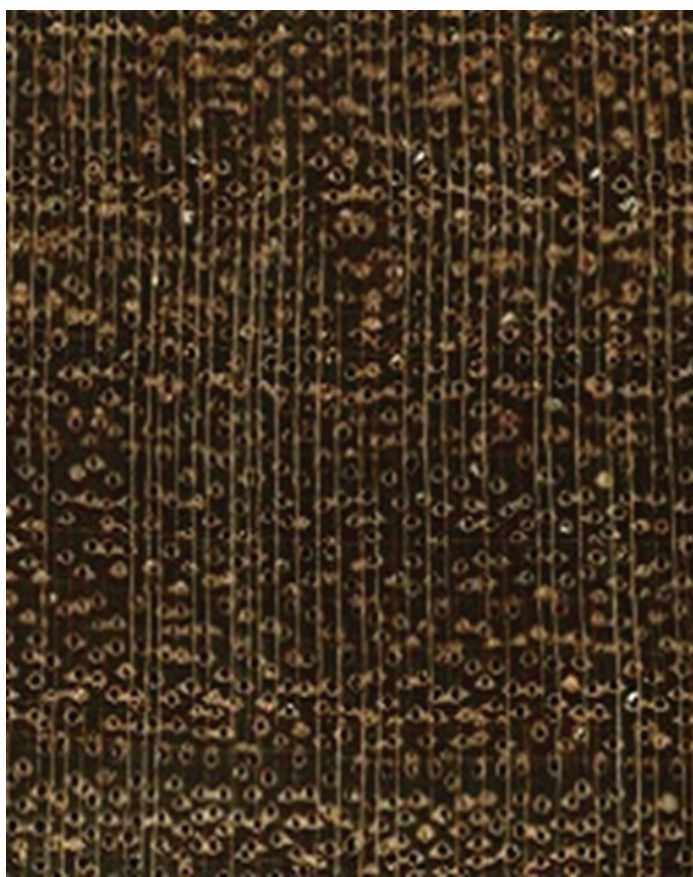

Figura 7. Fotomacrografia da madeira de Zeyheria tuberculosa - plano transversal, 10×.

Figure 7. Photomacrograph of the Zeyheria tuberculosa - transverse plane, $10 \times$.

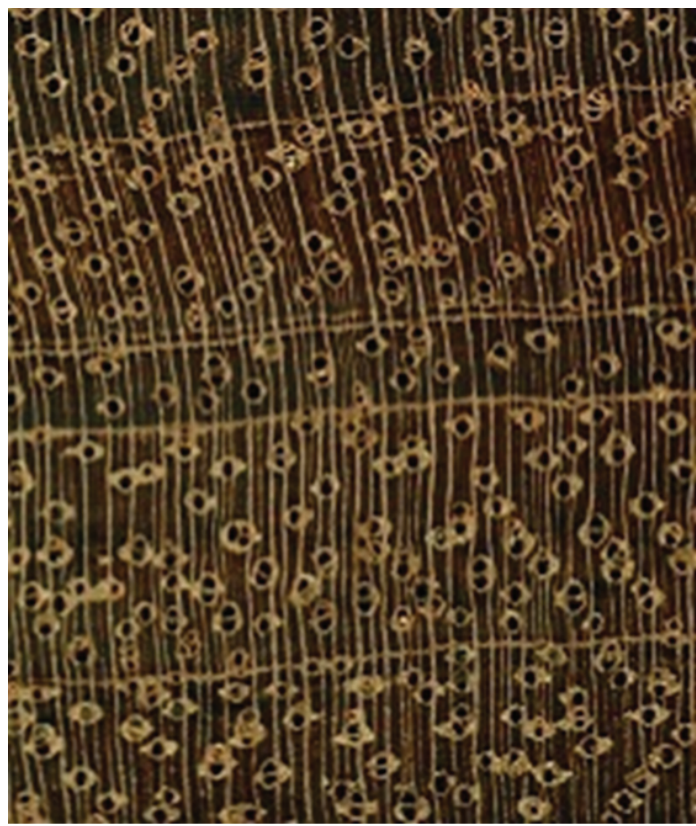

Figura 8. Fotomacrografia da madeira de Hymenaea courbaril - plano transversal, $10 \times$.

Figure 8. Photomacrograph of the Hymenaea courbaril wood - transverse plane, $10 \times$. 


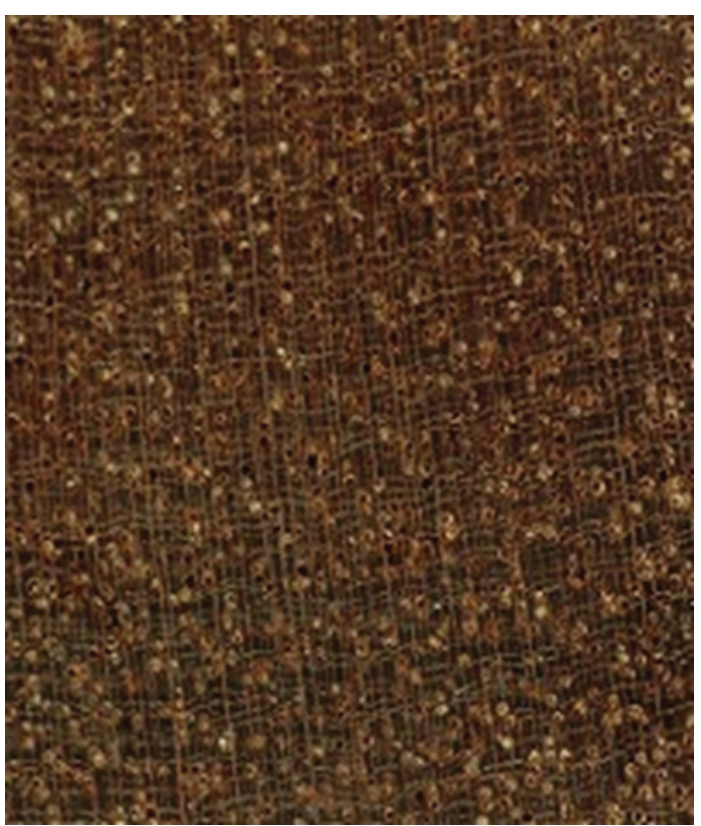

Figura 9. Fotomacrografia da madeira de Manilkara longifolia - plano transversal, $10 \times$.

Figure 9. Photomacrograph of the Manilkara longifolia - transverse plane, $10 \times$.

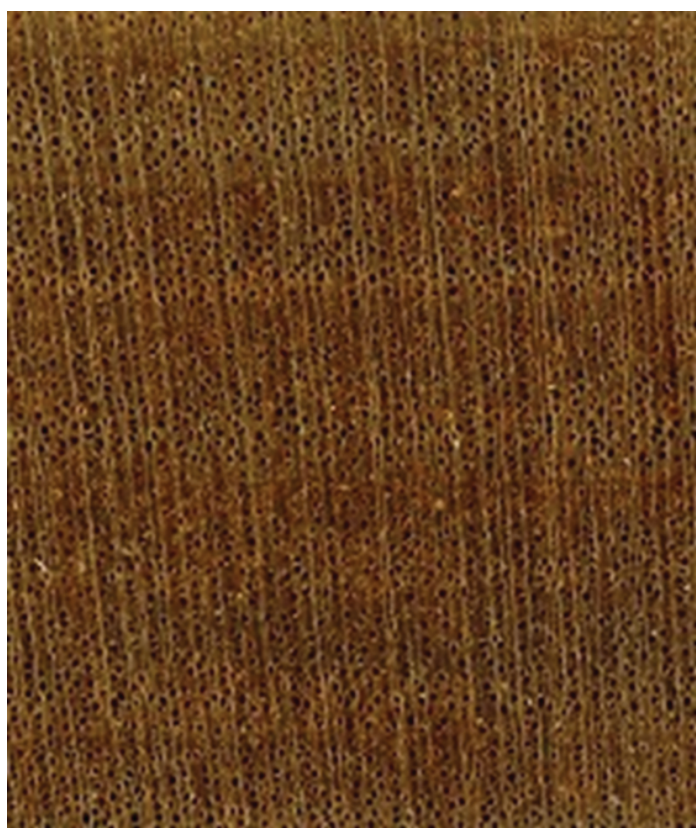

Figura 11. Fotomacrografia da madeira de Aspidosperma populifolium - plano transversal, $10 \times$.

Figure 11. Photomacrograph of the Aspidosperma populifolium wood - transverse plane, $10 \times$.

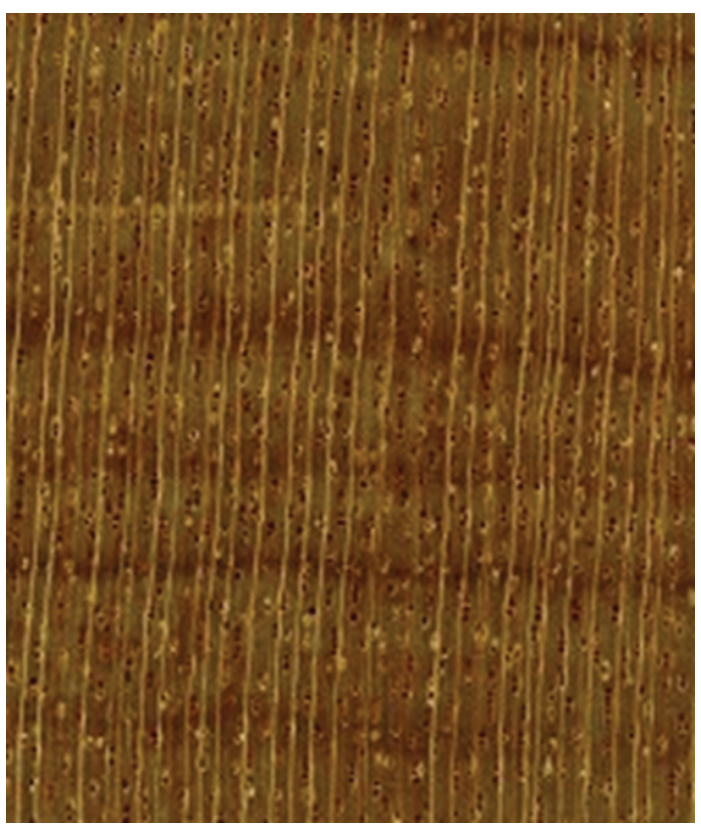

Figura 10. Fotomacrografia da madeira de Euxylophora paraensis - plano transversal, $10 \times$.

Figure 10. Photomacrograph of the Euxylophora paraensis wood - transverse plane, $10 \times$.

\section{CONCLUSÕES}

As descrições das características gerais das 11 madeiras mais comercializadas no Estado do Espírito Santo mostram o quanto é complexa a estrutura dessas madeiras, uma vez que, para praticamente todas as espécies, existe uma riqueza de detalhes anatômicos que são extremamente úteis para o seu correto conhecimento.

Tais descrições abordadas são de grande auxílio no reconhecimento dessas madeiras em nível de nomenclatura científica e poderão, sem nenhuma dúvida, contribuir para a comercialização mais racional destas pelo mercado madeireiro local e mesmo nacional.

As informações relativas às características gerais e anatômicas no nível macroscópico dessas madeiras, sem dúvida, poderão contribuir para garantir a lisura na comercialização, evitando fraudes e maior garantia na qualidade das madeiras utilizadas no Estado do Espírito Santo. 


\section{STATUS DA SUBMISSÃO}

Recebido: 30/01/2012

Aceito: 28/05/2012

Publicado: 30/09/2012

\section{AUTOR (ES) PARA CORRESPONDÊNCIA}

\section{Rejane Costa Alves}

Departamento de Engenharia de Estruturas, Escola de Engenharia, Universidade Federal de Minas Gerais - UFMG, Av. Antônio Carlos, 6.627, Campus Pampulha, CEP 31270-901, Belo Horizonte, MG, Brasil e-mail: recosta_88@hotmail.com

\section{REFERENCIAS}

Agência Pará. Economia: Sema libera 1,8 milhão de $\mathrm{m}^{3}$ de madeira para setor produtivo. Portal Remade; 2010. [cited2010maio 11].Availablefrom:http://www.remade. com.br/br/noticia.php? num=7340\&title $=$ Sema $\% 20$ libera $\% 201,8 \% 20$ milh\%E3o\%20de\%20m3\%20de\%20 madeira\%20para\%20setor\%20produtivo.

Centro de Inteligência em Florestas - CI Florestas. Produção Nacional - Produtos Madeireiros - Madeira Serrada - Total. [cited 2011 jan. 07]. Available from:

http://www.ciflorestas.com.br/dado. php?id=83\&n=producao_nacional_produtos_ madeireiros_madeira_serrada_-_total.

Comissão Panamericana de Normas Técnicas - COPANT. Descrição das características gerais e macroscópicas das madeiras de angiospermas dicotiledôneas. La paz: COPANT; 1974.

Chimelo JP. Identificação de madeiras. São Paulo: ESALQ/USP; 1992. p. 107-124. Apostila do Curso de Pós - Graduação em Ciências e Tecnologia de Madeiras.

Instituto de Pesquisas Tecnológicas - IPT. Manual de identificação das principais madeiras comerciais brasileiras. São Paulo; 1983.

Nahuz M. Mercado internacional sinaliza evolução. Revista da Madeira 2004; ed. 80. [cited 2010 abr. 19]. Available from: http:// www.remade.com.br/br/revistadamadeira materia.php? num $=549 \&$ subject $=$ Valor $\% 20$ Agregado\&title $=$ Mercado $\% 20$ internacional $\% 20$ sinaliza\%20evolu\%C3\%A7\%C3\%A3o.

Zenid GJ. Madeiras e suas características. In: Oliveira JTS, Fiedler NC, Nogueira M, editores. Tecnologias aplicadas ao setor madeireiro. Jerônimo Monteiro: Suprema; 2007.

Zenid GJ, Ceccantini GCT. Identificação botânica de madeiras. São Paulo: Laboratório de Anatomia e Identificação de Madeiras do Instituto de Pesquisa Tecnológica do Estado de São Paulo; 2007. 